\title{
An Appeal for Rationality in the Policy Activism Debate
}

\author{
John B. Taylor \\ STANFORD UNIVERSITY
}

My assignment for this paper is to provide an up-to-date review of the rational expectations debate about whether activist monetary and fiscal policies can improve macroeconomic performance. Preparing a review is particularly difficult at the present time, because we do not seem to be having much of a debate over policy activism. Looking back over the past five years since I prepared a similar review paper for this conference series [see Taylor (1980)], it now seems to me that the debate about policy effectiveness that raged between rational expectationists and other macroeconomists during the 1970s essentially ended in the early 1980s. Since then, only a few analytical or empirical studies of alternative policy proposals have been conducted, and more importantly little effort has been made to reach agreement among the various proposers, or even delineate specific reasons for disagreement. Clearly a renewal of discussion on these important issues is in order.

Rather than provide a detailed review of an old debate, this paper presents a case and outlines a framework for a new debate about policy. It argues that a good framework for debate is the rational expectations approach to policy evaluation that emerged from the policy ineffectiveness debate of the 1970 s, but which has been used far too rarely to study other activist policy issues. The paper includes an outline of the essential aspects of a rational expectations approach to the policy activism question.

\section{The End of the Policy Ineffectiveness Debate}

Rational expectations first became a big factor in the policy activism debate in the early 1970s when Thomas Sargent and Neil Wallace wrote their famous policy ineffectiveness paper. They showed-using an elemen- 
tary macroeconomic example based on Robert Lucas's then new model of the Phillips curve-that an active monetary policy could not be effective in stabilizing fluctuations in output and employment. Hence, a monetarist, constant-growth-rate rule for the money supply, such as the one proposed by Milton Friedman years before, was optimal: it could not be improved on by an activist or Keynesian countercyclical stabilization policy.

The Sargent-Wallace paper unsurprisingly ignited a great policy debate. The paper was soon followed up by demonstrations of empirical support for the Lucas model by Sargent and Robert Barro, and extensions of the Lucas model by Barro and others. Almost all Keynesian macroeconomists eventually joined in to register their disagreements. The policy ineffectiveness debate raged for much of the 1970s and completely replaced the monetary-fiscal policy debate among economists in most universities.

The early rational expectations proponents of the policy ineffectiveness view were quite explicit about their analytical framework and the assumptions that formed the underpinnings of their conclusions. For this reason, in my view, the debate had a relatively high degree of rationality compared to many debates about economics. It focused on specific issues of disagreement. In a relatively short period of time, bogus or irrelevant issues had been cast aside and the central reasons for disagreement had been isolated. Empirical tests of the crucial informational assumptions underlying the theory also came surprisingly quickly.

There is little doubt that the excitement surrounding this policy debate was responsible for stimulating the great interest in rational expectations shown by many young macroeconomists during the 1970s. The debate also stimulated thinking about alternatives to Lucas's theory of the Phillips curve-alternatives based on contracts and staggered wage setting with rational expectations in which the policy effectiveness property did not hold. Econometric techniques were improved in order to go beyond the simple Sargent-Wallace-type model and evaluate policy in large and possibly nonlinear models with rational expectations. Much as the monetary-fiscal policy debate, which was ignited by Milton Friedman's original monetarist proposals, generated empirical and theoretical research that improved our understanding of macroeconomic fluctuations, the policy ineffectiveness debate had similar positive fallout.

However beneficial, the policy ineffectiveness debate of the 1970s is now over. There is general agreement that it is the market-clearing assumptions, rather than the rational expectations assumptions, of the Lucas model that are responsible for the policy results; contract models with rational expectations introduced by Edmund Phelps, Stanley Fischer, myself, and others imply that policies that react to the state of the economy can improve macroeconomic performance. These contract models are 
now as much a part of rational expectations as the market-clearing models. In his textbook Michael Parkin (1984) has accordingly divided up the rational expectations school into two parts: the "new classical" school and the "new Keynesian" school. There also seems to be general agreement that the empirical support for the Lucas new classical model is weaker than the early Barro and Sargent studies showed. There is also general agreement that the new Keynesian models with rational expectations need some bolstering of their microeconomic foundations. Of course, others might characterize these areas of agreement somewhat differently. [See the survey by McCallum (1980) or a more recent one by myself (1985) for details and references.]

\section{The Current Deadlock}

One might have expected (as I did) that when the controversy over the policy ineffectiveness issue became resolved, rational expectations researchers in macroeconomics would then turn to other important, though perhaps less exotic, issues in the policy activism debate. Although there was agreement that the constant-growth-rate rule is not necessarily optimal, there still was relatively little agreement or even discussion about what a better rule might look like. Reflecting on the policy effectiveness debate, Stanley Fischer $(1980,226)$ noted, "After all, we do not know the optimal activist policy." There are many other issues to be resolved: how would we implement an activist policy rule if that would improve macroeconomic performance? Karl Brunner (1981) has raised questions about this practical issue. Can one deal in practice with the serious problem of lags and uncertainty in the effect of policy that the proponents of constant-growth-rate rules emphasize? Milton Friedman (1984) still feels that this is the fundamental problem with activist policy:

... slow, steady, monetary growth. That is not a necessary implication of monetarist theory. A believer in monetarist theory still can favor an activist monetary policy as a way to offset other changes in the economy.... [however] the monetary authorities have typically made matters worse. . . they have been a source of uncertainty and instability in the economy.

These are important areas of controversy in the policy activism debate that have not been resolved and about which there is little consensus or agreement. Yet serious research and evaluation of alternative policy rules using the rational expectations techniques that proved useful in resolving the earlier issues (or, for that matter, using any other analytical frame- 
work) is not underway at anything like the scale of research that we saw in the policy ineffectiveness debate. The policy activism debate has not moved in the direction that one would have thought.

I am not sure why this is so. Perhaps the apparent political success of supply-side economics discouraged those who thought scientific research in economics could have a hearing among policymakers. Perhaps the costly 1980-82 disinflation disillusioned some enthusiasts of the rational expectations assumption, though I do not feel it should have. Perhaps constant talk of budget deficits has made it difficult to concentrate on discussions about policy activism or made one feel terribly impractical in searching for long-run policy reforms.

Of course, policy talk has not stopped, and there have been interesting proposals for new, and not so new, policy rules to replace the monetarist constant-growth-rate rule: price rules, nominal GNP rules, interest-rate rules, gold-standard rules. Indeed there is now more talk and proposing than ever. The problem, in my view, is that there has been little attempt to evaluate these proposals within a theoretical or empirical framework that is specific enough to be criticized, debated, and eventually used to resolve disagreements.

This no-debate situation is troublesome at a time when there is a clear need for some consensus among macroeconomists. Lester Thurow (1983, $\mathrm{xv}$ ) expresses what is probably a commonly felt view: "The current intellectual disarray among economists is matched only by a parallel time of confusion during the early days of the Great Depression." The old Keynesian consensus is clearly gone, but nothing has yet replaced it. The lack of such a consensus leaves the economy vulnerable to economic policy actions based on little theoretical or empirical support. In his recent book on policy Herbert Stein $(1984,324)$ expresses the situation more passionately but no less accurately:

Although there is much talk about economic policy there is no debate. People say what they have always believed, or what they find it convenient to say, but there is no confrontation of the arguments. There is no effort to find the sources of disagreement or to reach agreement, perhaps because the participants think that the effort to change minds and reach agreement is hopeless. Talk about economic policy has become only a way of rallying one's own troops.

\section{What Is the Rational Expectations Approach?}

If the rational expectations approach is to provide a suitable framework for debating policy, it is necessary to have a general understanding of the approach. Despite numerous conferences and survey papers, there is still 
great confusion-especially among noneconomists and economists outside universities - about what the rational expectations approach to policy is. Consider, therefore, the following five general principles that I think summarize the rational expectations approach to macroeconomics.

First, people are forward-looking, and their future expectations can be modeled reasonably accurately by assuming that they have learned the basic statistical regularities of the business cycle, and they use this information to make unbiased (but not error-free) forecasts.

This, of course, is just the Muth definition of rational expectations applied to macroeconomics. It seems like a reasonable assumption for macroeconomic applications because many features of economic fluctuations are recurrent from one business cycle to another; there are established statistical regularities. Since business cycles have been observed for hundreds of years, it makes sense to assume that people have become familiar with them. Such a forward-looking unbiased forecasting assumption would not be reasonable for new unprecedented events for which there is no experience.

Second, macroeconomic policy should be stipulated and evaluated as a rule, rather than as one-time changes in the policy instruments.

Because people are assumed to be forward-looking, their expectations of future policy actions affect their current behavior and the state of the economy. Hence, in order to evaluate the effect of policy on the economy, we need to specify not only current policy changes but also future policy changes. In other words we need to specify a contingency plan that describes how policy will react to future events. Such a contingency is nothing more than a rule for policy. Of course, the contingency plan could specify a constant-growth-rate rule for the money supply, but more generally there will be some reaction from the state of the economy.

The rational expectations approach forces one to think about policy as a rule or a strategy. Once you are working with a rational expectations model, you soon realize that you have little choice but to specify policy as a rule. My own experience is that I have naturally specified policy rules in rational expectations policy evaluation studies without much thought about it one way or the other. This practical reason for thinking about policy as a rule does not seem to have been mentioned in the early discussions of rules versus discretion, but it does support the case for rules over discretion.

Note that the focus on rules does not mean that the effect of one-shot changes in policy should never be calculated with a rational expectations 
model. Such a calculation can be a useful thought experiment to help understand the workings of the model, but it is, of course, necessary to specify whether the change is anticipated or unanticipated, as well as whether it is temporary or permanent.

The famous critique of econometric policy evaluation put forth by Robert Lucas (1976) is the technical side of this principle. Lucas showed that traditional econometric models would give incorrect answers to policy evaluation problems if expectations were forward-looking and there was a change in the policy rule. Since these traditional models were based on adaptive backward-looking expectations, their parameters would change when the policy rule changed. This was the negative part of the critique and has clearly made policy analysts wary of using the traditional models. But there was also a positive side. The Lucas critique provided a general framework for modifying the traditional models; by stipulating policy as a rule it is possible to calculate by how much the parameters of the traditional models would change. Much technical econometric research by Thomas Sargent, Lars Hansen, and others has been devoted to developing such a framework.

Christopher Sims (1982) has recently argued that the focus of the rational expectations approach on alternative policy rules is irrelevant. $\mathrm{He}$ argues that we rarely get big changes in rules anyway, so that we might as well use reduced forms or conventional econometric models for policy. It is true that there is a utopian flavor to the rational expectations approach. The search is for big policy reforms that would improve economic welfare over a long period of time. The reforms would probably require changes in the policy-making institutions or the creation of new institutions. Such reforms are, by their very nature, rare. But they do occur. The creation of the Federal Reserve System, the departure from the gold standard, and the shift to floating exchange rates are all examples. These reforms seem to have had substantial effects on the economy. A careful analysis of the effects of future policy reforms therefore seems quite relevant.

Third, in order to get the benefits of a particular policy rule, it is necessary to establish a commitment to that rule.

As was first pointed out by Finn Kydland and Edward Prescott (1977), dynamic models with rational expectations can lead to problems of time inconsistency. They discovered this problem while attempting to compute optimal policy along the lines suggested by Lucas. In a dynamic model of investment and in a Phillips curve model, they found that once policymakers began on an optimal policy there was incentive in future periods for the policymakers to change the plan-to be inconsistent. Policymakers could make things better by being inconsistent. This was true 
even if the welfare function of policymakers was identical to that of people in the economy and did not change over time. However, by being inconsistent the policymakers would be likely to lose credibility; people would begin to assume that the policymakers would change, and this would lead to a new policy-making equilibrium that was generally inferior to the original policy plan of the policymakers. The implication is that to prevent this inferior outcome it is better to maintain a firm commitment to a policy rule.

There is a nice macroeconomic analogy to the macroeconomic time inconsistency problem: patent laws. By promising a patent to inventors, the patent laws stimulate inventive activity. Once a particular invention has been made, however, it is tempting to break the commitment and not give a patent. A policymaker who had the discretion to award patents each year would indeed be tempted not to do so. By holding back the patent, we avoid the economic inefficiencies of a monopoly. Fortunately, reneging on patents does not occur in practice because it is so clear that future inventive activity would suffer. As a result, we have patent laws that limit such discretion. The time inconsistency research suggests that discretion should be limited for similar reasons in macroeconomic policy. It should be emphasized that evaluating policy as a rule does not prevent time inconsistency. There still may be temptation to change the rule. The commitment to the rule is the important feature of this third principle.

The previous two principles together imply that a rational expectations analysis of "activist" policies is actually an analysis of policy rules with feedback from the state of the economy to the policy instruments. There is a big distinction between "discretionary" and "activist" policies. Those in favor of discretionary policy disagree with the whole concept of a ruleof-the-game approach, whether the rule is a feedback rule or a constant setting for the policy instruments; discretionary policy is formulated on a case-by-case and year-by-year basis with no attempt to commit or even talk about future policy decisions in advance. Activist and constantgrowth-rate policy rules have much more in common with each other than do activist policy rules and discretionary policy. Both types of policy rules involve commitments and lead to the type of policy analysis suggested by the rational expectations approach.

The next two principles are related to the types of economic models typically considered by rational expectations economists and to the factors they consider in determining whether a policy is good or not. On these two principles there is more variety among the different departments of the rational expectations school than there is on the first three principles.

Fourth, the economy is basically stable; after a shock the economy will eventually return to its normal trend paths of output and employment. 
However, because of rigidities in the structure of economy, not in expectation formation, this return may be slow.

Formal rational expectations models of economic fluctuations are usually dynamic systems continually disturbed by stochastic shocks. After each shock the economy has a tendency to return to a normal or natural growing level of output and employment, although there may be overshooting or a temporary cumulative movement away from normal. A smooth return is never observed in practice, however, because new shocks are always hitting the system. Since the economy is viewed as always being buffeted around by shocks, rational expectations economists must calculate a "stochastic equilibrium" rather than a "deterministic equilibrium" to describe the behavior of the economy. The combination of the stochastic shocks and the dynamics of rational expectations models is capable of mimicking the actual behavior of business cycles surprisingly well. The properties of the stochastic equilibrium are much like the actual behavior of business cycles.

The shocks can be due to many factors, but they usually have been portfolio preference shocks, productivity shocks, or price shocks. The dynamics are due to many possible rigidities in the economy, but pricewage rigidities and slow adjustment of capital (including inventories) have been the most important empirically.

Because of these rigidities, the impact of a shock to the economy takes time to sort itself out. Suppose, for example, that there is a shift in money velocity with people demanding to hold more money at any level of income and interest rates. Eventually the price level will fall so that the real supply of money is effectively increased. but if there are wage and price rigidities, this adjustment will take time: first the increase in money demand will cause an increase in interest rates; the higher level of interest rates will in turn depress demand for durables and have repercusions throughout the economy; depressed demand conditions will then begin to put downward pressure on prices; the fall in prices then will begin to raise the real supply of money; these prices will continue until the economy is back to its natural level of output and employment. The whole process could take more than a year.

Combined with these structural rigidities is the supposition that expectations are not restrained by similar rigidities. A shock can change expectations of inflation, exchange rates, and other variables overnight, even though there are rigidities that cause the economy to take additional time to fully adjust to the shock. The expectations take account of the structural rigidities, since these are part of the model. This combination of rigidities in the economy with perfectly flexible expectations is an essential feature of most rational expectations models. There has been a tendency 
to get expectations assumptions mixed up with structural assumptions about how markets work. Hence, the comment that expectations might be rational in flexible auction markets but not in sticky labor markets is frequently heard. These two types of assumptions should be usefully separated. (Again recall that rational expectations are meant to apply to recurrent events, not to unprecendented events. In response to a new event or a new policy rule, slow adjustment of expectations would be likely.)

There has been much research on price and wage rigidities in rational expectations models. The important general feature of this research is that prices and wages have a forward-looking feature, whether they are sticky or not. When workers and firms set wages and prices, they look ahead to the period during which the prices or wages will be in effect-to demand conditions, to the wages of other workers, and so on. This means that expectations of future policy actions will affect wage and price decisions, a property that is quite unlike Keynesian models of wage and price rigidities. The view that the economy will eventually return to normalhowever slowly-after a shock is also inconsistent with the Keynesian view of permanent underemployment equilibria.

Fifth, the objective of macroeconomic policy is to reduce the size (or the duration) of the fluctuations of output, employment, and inflation from normal or desired levels after shocks hit the economy. The objective is to be achieved over a long period of time that will, in general, include a large number of business cycle experiences. Future business cycle fluctuations are not viewed as less important than the current one.

By responding to economic shocks in a systematic fashion, economic policy can offset their impact or influence the speed at which the economy returns to normal. It thus can change the size of the fluctuations. How this should be done is a main subject of disagreement among proponents of different policy rules.

From a technical viewpoint the disagreement can be addressed by inserting alternative policy rules into a rational expectations model and calculating how each rule affects the variance of output, employment, and inflation in the stochastic equilibrium that describes the business cycle fluctuations. We want to choose a policy that provides the best economic performance as approximated by this stochastic equilibrium. One simple criterion is the minimization of the variance of output and inflation. Since in many models with price and wage rigidities there will be a trade-off between the reduction of output and inflation variability, it will usually be necessary to stipulate a welfare or loss function that reflects certain value 
judgments. Frequently, one policy will so dominate another than the particular welfare weights do not matter much, however.

Despite the need to make such value judgments the rational expectations approach is fairly specific about what the objectives of policy should be. Changing the natural or normal levels of output and employment is not the direct objective of stabilization policy from a rational expectations perspective; of course, it is possible that reduced variability of output or inflation could raise the secular growth rate of the economy or reduce the natural rate of unemployment. As a first approximation, these normal levels are not influenced by macroeconomic policy. The secular growth rate of the economy is influenced by tax policy and by the mix between fiscal and monetary policies. But it is the average setting of these instruments rather than their cyclical variations that is most important for long-term growth.

The average rate of inflation can obviously be influenced by monetary policy, and it is important to choose a target rate that maximizes economic welfare. The objective of macroeconomic policy, however, is to keep the inflation rate close to this target rate; that is, to minimize fluctuations around the target, regardless of what the actual value of the target is. Alternatively, if a zero inflation target is appropriate, the objective of policy is to keep the price level near some target; the specific target value itself is much less important.

\section{Some Proposals for Activist Policy Rules}

Although there have been too few analytical or empirical investigations of activist policy alternatives to monetarist rules, there clearly have been some. Mention of a few here may serve as a departure for discussion. I restrict myself to proposals being investigated by two of my macroeconomist colleagues at Stanford, Robert Hall (1984) and Ronald McKinnon (1984), as well as myself. Since the proposals are not exactly alike, there is room for discussion, and the examples are obviously not offered here as the final word.

\subsection{An elastic price rule}

Hall (1984) considers a policy rule in which the Fed manipulates its policy instruments in order to keep the deviations of the price level from its target level equal to eight times the deviation of the unemployment rate from its target level. The figure eight is chosen as an example; more generally, the exact number would be chosen after public discussion. The 
objective of the proposal is to stabilize fluctuations in both unemployment and the aggregate price. The level of unemployment rate is taken as given and equal to the natural rate. Equivalently, the policy attempts to establish an aggregate demand curve (in price-output space) that is steeper than a monetary rule or a nominal GNP rule and thereby less tolerant of output fluctuations than a monetarist rule.

Clearly this proposal fits into the policy evaluation framework outlined in the previous section. The emphasis is on cyclical fluctuations over a long period of time, the target level of unemployment is assumed to be unaffected by policy, and the policy evaluated is a rule. Discretion is not completely eliminated, however, because the Fed must decide the appropriate instrument setting to achieve the rule, but Hall does consider the problems of stating the rule in terms of magnitudes that the Fed does not directly control. The policy is evaluated by using a dynamic stochastic framework like that described under principle 4.

\subsection{An exchange rate rule}

McKinnon (1984) has been investigating an activist policy rule in which the Fed increases the growth rate of the money supply whenever the dollar exchange rate appreciates (relative to some target) against other hard currencies, particularly the mark and the yen. A lower exchange rate calls for a reduction of the money growth rate. Similarly the rule calls for the Bundesbank and the Bank of Japan to increase the growth rates of their money supplies whenever their exchange rates appreciate. In this sense the rule involves policy coordination between the countries. There is also coordination in maintaining agreement on the long-run trend path of the world money supply or at least the group money supply for the United States, Germany and Japan.

This exchange rate rule is designed to offset portfolio preference shocks that McKinnon views as arising partly via currency substitution between countries, and his analytical framework is directed toward such shocks. Although rational expectations is not entered explicitly into this framework, the quick movement of forward-looking exchange rate expectations in the face of rigidities elsewhere in the economy is one of the motivations behind focusing policy on the exchange rate.

\subsection{An activist money-supply rule}

In my own research I have investigated the properties of an activist money-supply rule that reacts to the state of the economy. Although a complex optimal rule was calculated for a particular rational expectations model using the overall approach outlined here, that rule turned out to be 
remarkably similar to a simpler rule in which the growth of the money supply is increased whenever real output is below its trend growth target; and by a little bit more when output is falling relative to its trend growth target. As a close approximation, the rule involved no accommodation of the money supply to inflation shocks. Hence, monetary policy has a stabilization role but no accommodation role. According to this framework this specific activist rule would work better than a monetarist rule.

An alternative to this proposal would have the stabilization role of monetary policy given over to a fiscal policy rule similar to the automatic stabilizers. This would make the monetary authorities responsible only for maintaining a fixed money-growth rate, which could reduce temptation to accommodate inflation. It would also prevent monetary policy from having international repercussions when attempting to react to domestic policy disturbances. However, allocation of all stabilization policy to a fiscal policy rule might require some explicit attempt to deal with interestsensitive investment demand.

\section{Concluding Remarks}

My aim here has been to present a rational expectations framework within which a number of issues in the policy activism controversy might be fruitfully discussed and debated. The hope is that such a framework might bring more rationality to a debate that now seems to be in a slump. The framework involves a number of specific features that I think are reasonable and on which there might be some agreement, but it is by no means a straitjacket. It leaves plenty of interesting modeling questions open to the investigator of a particular problem.

\section{References}

Brunner, Karl. 1981. The case against policy activism. Lloyds Bank Review No. 139.

Fischer, Stanley. 1980. On activist monetary policy with rational expectations. In Rational Expectations and Economic Policy, ed. S. Fischer. Chicago: University of Chicago Press.

Friedman, Milton. 1984. Has monetarism failed? Manhattan Report 4: No. 3. New York: Manhattan Institute for Policy Research.

Hall, Robert E. 1984. Monetary strategy with an elastic price standard. Federal Reserve Bank of Kansas City Conference on Monetary Policy.

Kydland, Finn, and Edward C. Prescott. 1977. Rules rather than discretion: The inconsistency of optimal plans. Journal of Political Economy 85: 473-91.

Lucas, Robert E., Jr. 1976. Econometric policy evaluation: A critique. CarnegieRochester Conference Series of Public Policy, Vol. 1. Amsterdam: NorthHolland. 
1980. Rules, discretion, and the role of the economic advisor. In Rational Expectations and Economic Policy, ed. S. Fischer. Chicago: University of Chicago Press.

McCallum, Bennett T. 1980. Rational expectations and macroeconomic stabilization policy: An overview. Journal of Money, Credit and Banking 12: 716-46.

McKinnon, Ronald I. 1984. An International Standard for Monetary Stabilization. Washington, D.C.: The Institute for International Economics. (Distributed by M.I.T. Press.)

Parkin, Michael. 1984. Macroeconomics. Englewood Cliffs, N.J.: Prentice-Hall.

Sims, Christopher. 1982. Policy making with econometric models. Brookings Papers on Economic Activity 1.

Stein, Herbert. 1983. Presidential Economics: The Making of Economic Policy from Roosevelt to Reagan and Beyond. New York: Simon and Schuster.

Taylor, John B. 1980. Recent developments in the theory of stabilization policy. Stablization Policy: Lessons for the 1970's and Implications for the 1980's, ed. L. Meyer. Federal Reserve Bank of St. Louis.

1981. Stabilization, accommodation, and monetary rules. American Economic Review 70: 145-49.

n.d. Rational expectations models in macroeconomics. In Frontiers in Economics, ed. K. Arrow and S. Honkapojha. Oxford: Basil Blackwell. Forthcoming.

Thurow, Lester. 1983. Dangerous Currents: The State of Economics. New York: Random House. 